American Journal of Pharmacology and Toxicology 4 (4): 177-185, 2009

ISSN 1557-4962

(C) 2009 Science Publications

\title{
Cryptolepine Provokes Changes in the Expression of Cell Cycle Proteins in Growing Cells
}

\author{
${ }^{1}$ Charles Ansah and ${ }^{2}$ Nigel J. Gooderham \\ ${ }^{1}$ Department of Pharmacology, College of Health Sciences, \\ Kwame Nkrumah University of Science and Technology, Kumasi, Ghana \\ ${ }^{2}$ Section of Molecular Toxicology, Division of Biomedical Sciences, \\ Faculty of Medicine, Imperial College London, London, SW7 2AZ, UK
}

\begin{abstract}
Problem statement: Cryptolepine, the antimalarial plant alkaloid is cytotoxic to mammalian cells, but there is rather little understanding of the possible mechanisms involved in the cell-kill action of cryptolepine. Approach: We examined mammalian cells exposed to cryptolepine $(0.5-5.0 \mu \mathrm{M})$ for effects on the cell cycle and associated alterations in the levels of major regulatory proteins using immunoblotting and flow cytometry. Results: Cryptolepine $(0.5-5.0 \mu \mathrm{M})$ caused a dosedependent increase in the sub-G1 from 3.03-31.64\% in HepG2 and from 13.80-42.82\%) in MCL-5, cell lines with wild p53. Additionally, G1 fractions increased to 69.17 and $37.49 \%$ in HepG2 and MCL-5 respectively. In both cell lines, the G1 increase was associated with temporal increases in MDM2 protein, p53 protein and p53's target cyclin-dependent kinase inhibitor, p21. Consistent with the $\mathrm{G} 1$ arrest was also a decrease in cyclin $\mathrm{D}_{1}$, cyclin $\mathrm{A}$ and the hyperphosphorylated form of retinoblastoma protein, the key modulators of the G1 checkpoint in HepG2 cells. In cells with null-p53 (SKOV3) however, a p53-independent G2 arrest was evident. Conclusion: The study showed that, though cryptolepine is cytotoxic irrespective of the p53 status of the cell line, its effect on the cell cycle appears to depend on the p53 status of the cell line. The potent cell-kill action of cryptolepine and its ability to evoke cell cycle arrest in susceptible cells favor its anticancer potential.
\end{abstract}

Key words: Cryptolepine, cell cycle arrest, p53

\section{INTRODUCTION}

Cryptolepine, the major alkaloidal component of the West African herbal Cryptolepis sanguinolenta ${ }^{[1,2]}$, is a candidate antitumor agent ${ }^{[3,4]}$. Cryptolepine exhibits potent cytotoxic activity against a wide variety of mammalian cell lines in vitro ${ }^{[3-5]}$ but the molecular mechanisms underpinning the toxicity is not fully understood. The DNA intercalating effects of the compound $^{[6]}$ and the generation of reactive oxygen species $^{[7]}$ may well contribute to the cytotoxic effects of cryptolepine. Recent studies also suggest that cryptolepine might induce apoptosis or necrosis depending on the cell type ${ }^{[8]}$. Cellular responses in the form of cell cycle arrest are a common mechanism of chemical-induced toxicity. Dassonneville and coresearchers ${ }^{[5]}$, reported a $\mathrm{G} 2 / \mathrm{M}$ arrest with cryptolepine in P388 murine leukaemia cells but no detectable cell cycle changes were observed with HL-60 human cells. However, there is little understanding on the possible effect of cryptolepine on the cell cycle and its regulatory proteins. p53 is a key protein known to play a central role in response to cell toxicity, including mediating cell cycle arrest ${ }^{[9,10]}$. Our previous report ${ }^{[4]}$ showed that cryptolepine induced a dose-dependent increase in the sub-G1 population of V79 cells (with a mutated non-functional p53) ${ }^{[11]}$ without any obvious block in the G1, S or G2/M phases. Here, we have used HepG2, a human hepatoblastoma cell line with wildtype p53; MCL-5 cells with wild-type $\mathrm{p} 53^{[12]}$ and SKOV3 cells with null-p53 ${ }^{[13]}$ with the objective of monitoring the effect of cryptolepine on the cell cycle and the changes associated with the expression of key proteins involved in cell cycle control.

\section{MATERIALS AND METHODS}

Chemicals and reagents: Cryptolepine (purity >99\%) was a kind donation from Dr J Addae-Kyereme, formerly of the Department of Pharmaceutical

Corresponding Author: Charles Ansah, Department of Pharmacology, College of Health Sciences, Kwame Nkrumah University of Science and Technology, Kumasi, Ghana Tel: (+ 233) 0(51) 60372 Fax: (+233)0(51) 60137 
Chemistry, College of Heath Sciences, Kwame Nkrumah University of Science and Technology, Kumasi, Ghana. Propidium Iodide (PI), RNase, acrylamide/bis-acrylamide, Sodium Dodecyl Sulphate (SDS) solution, tween 20, ammonium persulphate, N, $\mathrm{N}, \mathrm{N}^{\prime}, \mathrm{N}^{\prime}$-Tetramethylethylenediamine (TEMED), tris base, glycerol, bromophenol blue and $\beta$ mercaptoethanol were purchased from Sigma Chemical Co. (Poole, England). Glycine and methanol were obtained from BDH Lab Supplies (Poole, England). Primary antibodies were purchased from Santa Cruz Biotechnology (Santa Cruz, CA) and secondary antibodies were from Sigma Chemical Co. (Poole, England). Bicinchoninic Acid (BCA) protein reagent was purchased from Pierce (Rockford, IL).

Cell lines and conditions: HepG2, a human hepatoma cell line was cultured in Minimum Essential Medium (MEM) supplemented with $10 \%$ foetal calf serum (FCS). SKOV3, a human ovary adenocarcinoma cell line was grown in McCoy's 5a (Invitrogen, Paisley, Scotland, UK). MCL-5, a human lymphoblastoid cell line ${ }^{[14]}$ was obtained from Gentest (Woburn, MA, USA). These were grown in Gentest RPMI 1640 media (without histidine and with $2 \mathrm{mM}$ histidinol for plasmid selection), supplemented with 9\% horse serum. Additionally, all media contained $2 \mathrm{mM}$ L-glutamine and 100 units of penicillin/streptomycin. MCL-5 cells were grown to a density of $10^{6}$ cells $\mathrm{mL}^{-1}$ and subcultured to $2.5 \times 10^{5}$ cells mL ${ }^{-1}$ every $48 \mathrm{~h}$. Hygromycin $\mathrm{B}\left(100 \mu \mathrm{g} \mathrm{m}^{-1}\right)$ was added at each sub-culturing for plasmid maintenance. All cell lines were routinely maintained at $37^{\circ} \mathrm{C}$ in a humidified atmosphere of $5 \%$ $\mathrm{CO}_{2} / 95 \%$ air.

Cell cycle analysis by flow cytometry: One million $\left(1 \times 10^{6}\right)$ exponentially growing cells were seeded in $5 \mathrm{~mL}$ pre-warmed media overnight in $25 \mathrm{~cm}^{2}$ flasks before treatment with vehicle (medium) or cryptolepine (0.5$5.0 \mu \mathrm{M}$ prepared in media). Immediately after the treatment period, cells were harvested by centrifugation $(200 \times \mathrm{g})$, washed twice with PBS and then fixed in $1 \mathrm{~mL}$ of $70 \%$ ethanol at $-20^{\circ} \mathrm{C}$ for $24 \mathrm{~h}$. After removing the ethanol by centrifugation, cells were resuspended in $1 \mathrm{~mL}$ of PBS solution containing $5 \mu \mathrm{g} \mathrm{mL}{ }^{-1}$ Propidium Iodide (PI) and $100 \mu \mathrm{g} \mathrm{mL}^{-1}$ RNase and incubated in a water bath in the dark at $37^{\circ} \mathrm{C}$ for $30 \mathrm{~min}$. Samples were then analyzed on a Becton Dickinson FACScan flow cytometer. PI was excited at $488 \mathrm{nM}$ and fluorescence analyzed at $620 \mathrm{nM}$. Ten thousand $(10,000)$ cells were analyzed per data point.

Immunoblotting: Treated cells were harvested by centrifuging at $200 \times \mathrm{g}$ for $10 \mathrm{~min}$. Cell pellets were lysed by rapid freeze/thaw and sonication for $30 \mathrm{sec}$ with $500 \mu \mathrm{L}$ of PBS containing a protease inhibitor cocktail $\left(2 \mu \mathrm{g} \mathrm{m}^{-1}\right.$, Sigma Chemical Co. Ltd, Poole, England). Protein concentration of the samples was determined by the Bradford method using a BCA protein assay kit (Pierce, Rockford, IL) according to the manufacturer's instructions. Cell lysates were diluted two fold with sample buffer $(0.5 \mathrm{M}$ Tris- $\mathrm{HCl}, 10 \% \mathrm{w} / \mathrm{v}$ SDS, $0.5 \%$ bromophenol blue and $50 \mu \mathrm{L} \quad \beta$ mercaptoethanol) and heated at $95^{\circ} \mathrm{C}$ for $5 \mathrm{~min}$. Proteins were electrophoretically resolved at $(200 \mathrm{~V})$ in a running buffer $(25 \mathrm{mM}$ Tris, $192 \mathrm{mM}$ glycine, $1 \%$ SDS, $\mathrm{pH}$ 8.3). Fractionated proteins were then transferred on to Hybond-C nitrocellulose membranes for $90 \mathrm{~min}$ at $450 \mathrm{~mA}$ in a transfer buffer $(25 \mathrm{mM}$ Tris, $192 \mathrm{mM}$ glycine, 20\% v/v methanol, $\mathrm{pH}$ 8.3). Uniform protein transfer was checked by Ponceau red staining before blocking the membranes with 5\% non-fat milk powder in PBST (25 mM phosphate buffered saline, containing $0.1 \%$ tween-20) for $1 \mathrm{~h}$. Following three consecutive washings with PBST each of $10 \mathrm{~min}$ duration, the blots were incubated with the primary antibody in $5 \%$ non-fat milk overnight at $4^{\circ} \mathrm{C}$. After washing the blot three times (15 min each with PBST), the blots were incubated with the appropriate dilutions of horseradish peroxidase-conjugated secondary antibody (HRP-conjugated secondary antibody). Proteins were then visualized using an Enhanced Chemiluminescence (ECL) detection kit (Pierce, IL) according to the manufacturer's instructions. Equal protein loading for each lane was confirmed using an antibody to $\beta$-actin.

\section{RESULTS}

Effects of cryptolepine on the cell cycle of growing cells: We reported previously the high sensitivity of V79 cells (with a mutated non-functional p53) ${ }^{[11]}$ to the toxicity of cryptolepine ${ }^{[4]}$. Because of the central role of p53 in cell cycle control ${ }^{[10]}$, we investigated the effect of CLP on cell lines of different p53 status.

In SKOV3 ovarian adenocarcinoma cell line with null-p53, changes in the sub-G1 population remained largely unchanged even at the highest dose of $5.0 \mu \mathrm{M}$ cryptolepine, following treatment for $24 \mathrm{~h}$ (Fig. 1, Panel a). However, there was an increase in the G2/M population from the control value of $46.98-85.43 \%$ at a concentration of $5.0 \mu \mathrm{M}$ cryptolepine (Fig. 1, Panel a), suggesting that cryptolepine inhibits cell division in this cell line. In HepG2 hepatoblastoma cell line with wildtype $\mathrm{p} 53$, there were no major changes to the $\mathrm{S}$ and G2/M phases following treatment with increasing concentrations of cryptolepine (Fig. 1, Panel b). 
Am. J. Pharm. \& Toxicol., 4 (4): 177-185, 2009
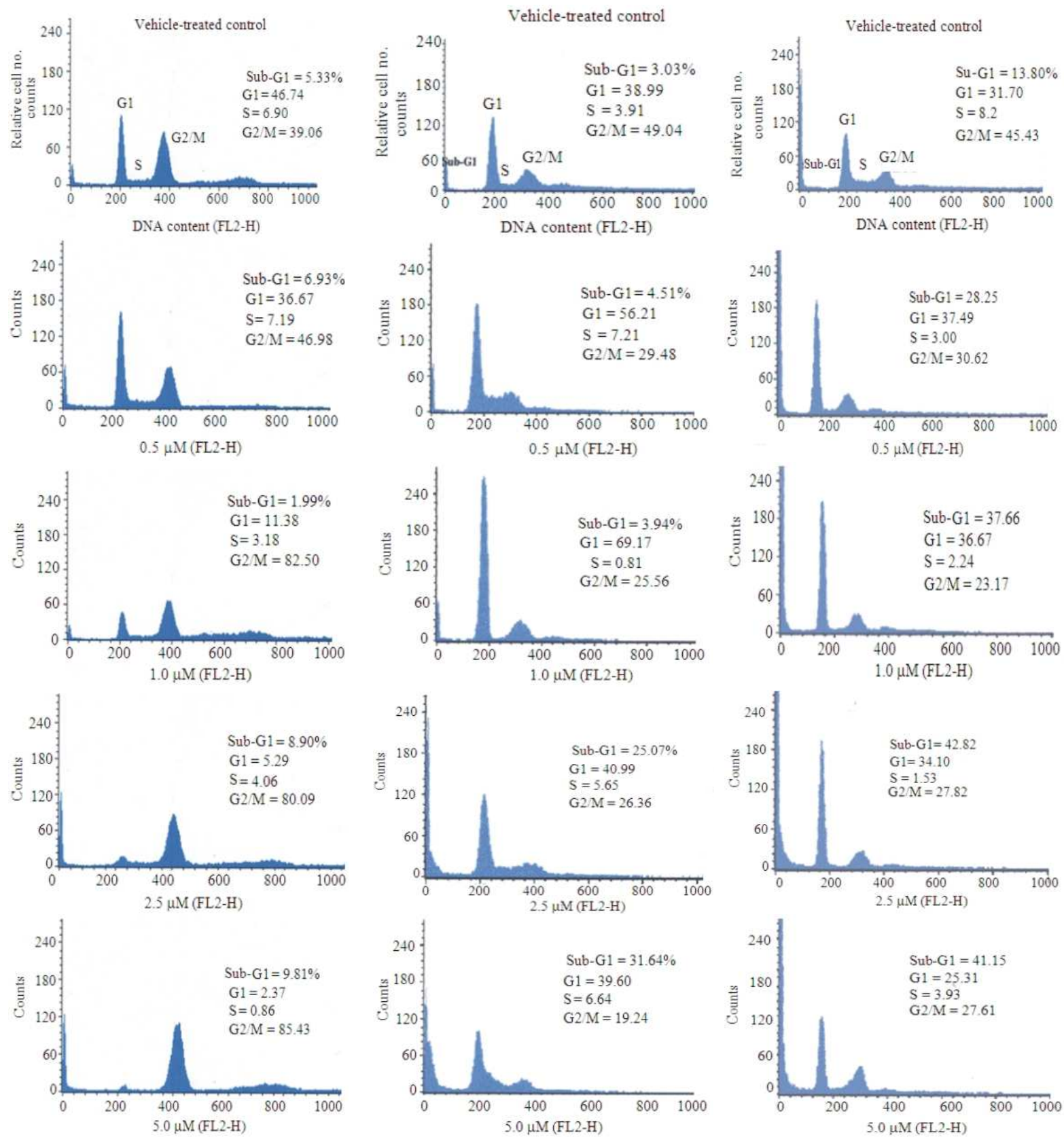

(a)

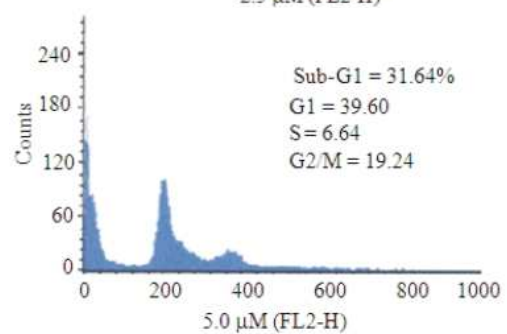

(b)

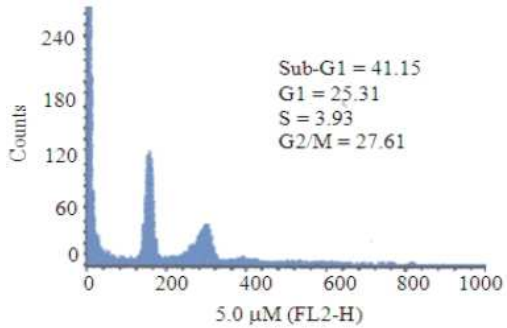

(c)

Fig. 1: The effect of cryptolepine on the cell cycle distribution of SKOV3 (Panel a), HepG2 (Panel b) and MCL-5 (Panel c) cells. Cells were treated at the indicated concentrations for $24 \mathrm{~h}$, harvested immediately after the treatment period, fixed and analyzed with the FACScan flow cytometer. Ten thousand cells were analyzed per sample. Histograms are representatives of three experiments with similar results

However, a dose-dependent increase in the subG1 fraction (representing the dead/dying cell population) compared to vehicle-treated control was observed (Fig. 1, Panel b). The percentage of dead cells increased from a vehicle-treated control value of 3.03$31.64 \%$ at $5.0 \mu \mathrm{M}$ of cryptolepine for $24 \mathrm{~h}$. 
Additionally, there was a substantial increase in the G1 fraction which peaked at $69 \%$ in cells treated $1.0 \mu \mathrm{M}$ (Fig. 1, Panel b). At higher doses, an increase in the sub-G1 population appeared to be the predominant effect consistent with the cytotoxic effects of the agent. Together, the effect of cryptolepine on HepG2 cells, a cell line with wild-type p53, could be generalized as an increase in the sub-G1 and G1 fractions.

To further examine the effect of cryptolepine on another cell with wild-type p53, MCL-5, a human lymphoblastoid cell line was used. Interestingly, this cell line showed a cell cycle profile similar to the HepG2 cells, causing a dose-dependent increase in the sub-G1 population (Fig. 1, Panel c). Increase in the G1 population was also evident after $24 \mathrm{~h}$ exposure to $0.5 \mu \mathrm{M}$ cryptolepine (Fig. 1, Panel c). With increasing concentrations, the G1 population diminished in favor of increased sub-G1 population (Fig. 1, Panel c).

Effect of cryptolepine on p53: SKOV3, an ovarian adenocarcinoma cell line with null $\mathrm{p} 53^{[13]}$ was treated with cryptolepine $(0.5-5.0 \mu \mathrm{M})$ and its p53 status confirmed by immunoblotting with a p53 antibody. p53 was not detected in either vehicle or treated cells (data not shown), suggesting that the cryptolepine-induced G2 arrest observed in the cell cycle studies involved a p53-independent mechanism. Cryptolepine caused a dose-dependent increase in p53 protein levels (Fig. 2, Panel a) in HepG2 cells and MCL-5 cells (Fig. 2, Panel b). Time-course analysis of p53 using $2.5 \mu \mathrm{M}$ CLP showed persistent increase at all time-points up to $24 \mathrm{~h}$. The increase in p53 was consistent with the G1 arrest observed in the cell cycle studies in HepG2 cells (Fig. 1, Panel b) and MCL-5 cells (Fig. 1, Panel c).

Effect of cryptolepine on p53 target gene products: The observation that cryptolepine induce G1 arrest accompanied by p53 up-regulation in p53-wild type cells prompted us to study the possible effect of cryptolepine on p53 target gene products as p53induced growth arrest is thought to be mediated by the p53-dependent transactivation of $\mathrm{p} 21^{[15]}$.

SKOV3 cells were treated with cryptolepine (0.5$5.0 \mu \mathrm{M})$. In the vehicle-treated control and at all concentrations of cryptolepine, p21 was not detected in the SKOV3 cell line. These results confirm the null-p53 status reported for this cell ${ }^{[13]}$.

In HepG2 cells, temporal changes in p21 protein expression were studied following treatment with cryptolepine for up to $24 \mathrm{~h}$. Only a marginal increase in p21 over vehicle-treated controls was observed after $4 \mathrm{~h}$, yet by $8 \mathrm{~h}$, a massive increase over vehicle-treated control was observed (Fig. 3, Panel a). The increase,

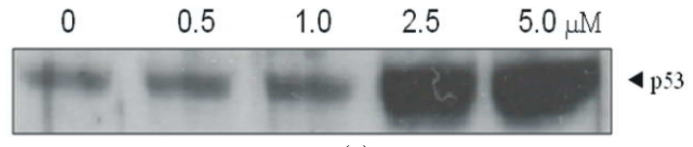

(a)

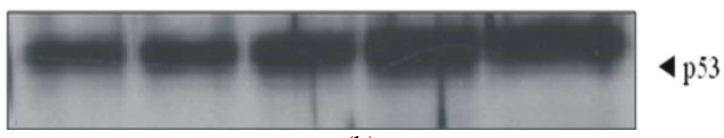

(b)

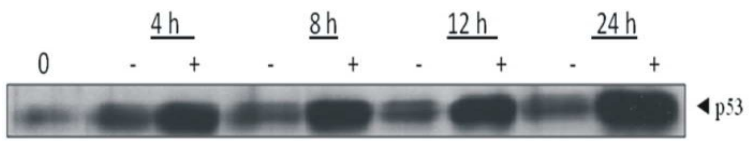

(c)

Fig. 2: Dose and time-dependent induction of p53 protein by cryptolepine. (a) Panel a shows the effect of cryptolepine $(0.5-5.0 \mu \mathrm{M})$ on p53 expression in HepG2 and (b) Panel b in MCL5 cells after $24 \mathrm{~h}$ treatment. Panel $\mathrm{c}$ is the time-course for cryptolepine $(2.5 \mu \mathrm{M})$ in HepG 2 cells over a $24 \mathrm{~h}$ period. Total cellular proteins were resolved by SDS-PAGE, blotted on to nitrocellulose membrane and probed with a rabbit polyclonal antibody against p53. In (c) Panel c, (+) and (-) lanes represent lysates from cells treated with and without cryptolepine respectively. Representative blots from two experiments with similar results are shown

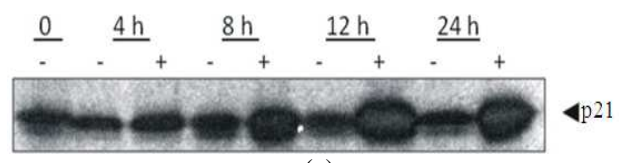

(a)

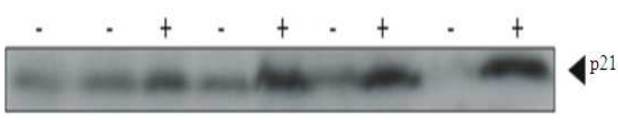

(b)

Fig. 3: Induction of p21 protein expression by cryptolepine $(2.5 \mu \mathrm{M})$ in HepG2 (Panel a) and MCL-5 (Panel b) cells over a $24 \mathrm{~h}$ period. Total cellular proteins were resolved by SDS-PAGE, blotted on to nitrocellulose membrane and probed with a rabbit polyclonal antibody against p21. (+) and (-) lanes represent lysates from cells treated with and without cryptolepine respectively. Representative results from two experiments are shown 
Am. J. Pharm. \& Toxicol., 4 (4): 177-185, 2009

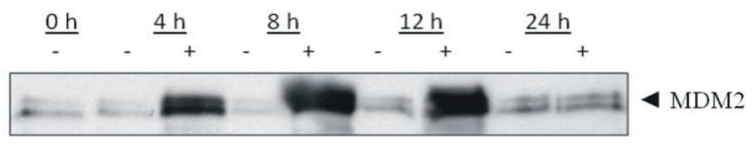

(a)

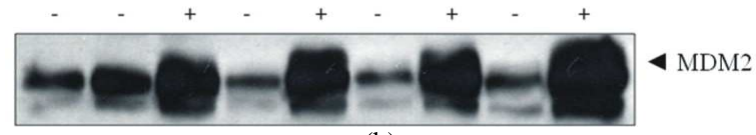

(b)

Fig. 4: Induction of MDM2 protein expression changes by cryptolepine $(2.5 \mu \mathrm{M})$ in HepG2 (Panel a) and MCL-5 (Panel b) cells over a $24 \mathrm{~h}$ period. Total cellular proteins were resolved by SDSPAGE, blotted on to nitrocellulose membrane and probed with a rabbit polyclonal antibody against MDM2. (+) and (-) lanes represent lysates from cells treated with and without ligands respectively. Representative results from two separate experiments with similar results

which was time-dependent peaked at $12 \mathrm{~h}$ but remained elevated compared to the negative control at $24 \mathrm{~h}$ (Fig. 3, Panel a). The changes in p21 correlated well with the p53 expression in this cell line (Fig. 2). In the MCL-5 cell line, cryptolepine-induced p53 and p21 expression patterns similar to those observed with the HepG2 cells.

MDM2 is another key target for p53 transcriptional up-regulation ${ }^{[16]}$. Time-dependent expression changes in this protein were therefore studied in the p53 wildtype HepG2 and MCL-5 cells. In both cell lines, treatment with cryptolepine $(2.5 \mu \mathrm{M})$ induced a timedependent increase in MDM2 expression (Fig. 4). Whilst this increase continued over the $24 \mathrm{~h}$ time period in the MCL5 cells, the effect peaked at $12 \mathrm{~h}$ in the HepG2 cells and had dramatically declined by $24 \mathrm{~h}$.

To explore further the cell cycle effects of cryptolepine on wild-type p53 cells, the expression of pRB and key cyclins involved in cell cycle control were examined in HepG2 cells. Treatment with $2.5 \mu \mathrm{M}$ cryptolepine resulted in a decrease in the $\mathrm{pRB}$ protein expression and pRB phosphorylation (hyperphosphorylated pRB) (ppRB) in a timedependent manner (Fig. 5, Panel a), strongly suggesting that $\mathrm{pRB}$ has a role in cryptolepine-induced $\mathrm{G} 1$ arrest in HepG2 cells.

The effect of cryptolepine on the expression changes of cyclin $D_{1}$ was also studied. Cyclin $D_{1}$ expression was constant for the first $4 \mathrm{~h}$ for both vehicle- and cryptolepine-treated cells (Fig. 5, Panel b). Between 8 and 24 h however there was a massive up-regulation in vehicle-treated controls compared to cryptolepine-treated samples (Fig. 5, Panel b).

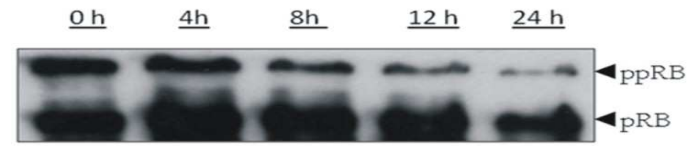

(a)

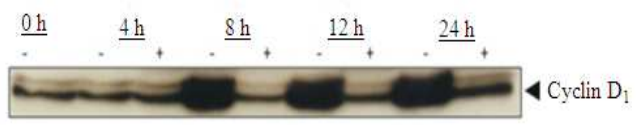

(b)

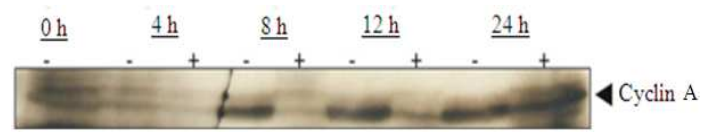

(c)

Fig. 5: Effect of cryptolepine $(2.5 \mu \mathrm{M})$ on pRB phosphorylation (Panel a) and cyclin $\mathrm{D}_{1}$ (Panel b)/cyclin A (Panel c) protein expression in HepG2 cells over $24 \mathrm{~h}$. In Panel a, the upper band ppRB represents the hyperphosphorylated and the lower band pRB, the hypophosphorylated form of the retinoblastoma protein. Total cellular proteins were resolved by SDS-PAGE, blotted on to nitrocellulose membrane and probed with the corresponding antibodies. (+) and (-) lanes represent lysates from cells treated with and without cryptolepine respectively. Representative results from two separate experiments with similar results

These observations correlated well with the cell cycle data where CLP caused G1 arrest between 8 and $24 \mathrm{~h}$ (Fig. 1, Panel b). The pattern of expression of cyclin A followed a similar pattern to cyclin $\mathrm{D}_{1}$ (Fig. 5, Panel c). It was virtually undetectable in cryptolepine-treated samples at 8 and $12 \mathrm{~h}$ compared to vehicle treated controls. The level at $24 \mathrm{~h}$, which was comparable to control levels, was expected as G1 accumulation was not observed at this time point.

\section{DISCUSSION}

The anti-malarial action of cryptolepine ${ }^{[17-19]}$ and its cytotoxic activity ${ }^{[3-5]}$ are well established. However, there is little understanding of the molecular events associated with the cytotoxicity, though this could be linked to the DNA intercalating effects of the compound $^{[6]}$ or the ability of cryptolepine to generate reactive oxygen species ${ }^{[7]}$. Because growth changes in the form of cycle arrest is a common mechanism of chemical-induced toxicity, we hypothesized that cryptolepine toxicity could be associated with cell cycle changes. 
Am. J. Pharm. \& Toxicol., 4 (4): 177-185, 2009

Dassoneville et $a .^{[5]}$ showed a G2/M arrest with cryptolepine in P388 murine leukaemia cells but no detectable cell cycle changes were observed in HL-60 human cells. They suggested that the HL-60 leukaemia cells were prone to enter apoptosis rather than cell cycle delay due to the lack of functional p53. This limited knowledge on the cellular effects of cryptolepine warranted further studies. We have therefore examined the effects of cryptolepine on the cell cycle using cell lines with different p53 status.

Studies on SKOV3 cells, a human ovarian adenocarcinoma p53-null cell line ${ }^{[13]}$ in the present study showed a cryptolepine-induced G2/M arrest. Immunoblotting of treated cell lysates confirmed the lack of p53 expression and its target cdk inhibitor p21 suggesting that the observed G2/block was independent of p53 and p21. Cryptolepine is reported to be a topoisomerase II (topo II) inhibitor ${ }^{[3,20]}$. Clifford et al. ${ }^{[21]}$ reported the induction of $\mathrm{G} 2$ arrest by etoposide (a topoisomerase II inhibitor) in HT1080 cells expressing a dominant-negative form of p53 by etoposide. This suggests that the etoposide-induced G2 arrest was also independent of p53. This report together with our present observation of cryptolepine-induced G2 arrest in SKOV3 cells would suggest a causal relationship between the reported topo II inhibitory action of cryptolepine and the observed G2 arrest in SKOV3 cells. Chromosomal segregation requires active topo II whose activity peaks at mitosis; as a result, topo II targeting agents are known to arrest the cell cycle at $\mathrm{G} 2 / \mathrm{M}^{[22,23]}$. It is proposed here that the cryptolepineinduced G2 arrest in SKOV3 cells may be due to its topo II inhibitory actions, independent of p53.

Considering the critical role of p53 as the "genomic guardian ${ }^{[24]}$,, we performed investigations in HepG2 and MCL-5, which are p53 wild-type cells. In response to genotoxic stress, mammalian cells activate the cell cycle checkpoints at the G1/S and G2/M transitions $^{[25]}$ and p53 is an important regulator of these checkpoint functions ${ }^{[26-28]}$ by inducing a cell cycle arrest. This process extends the time available for DNA repair before the cell enters the critical $S$ and $M$ phases of the cell cycle. In the event of severe and irreparable damage, p53 launches the apoptotic pathway by directly activating death genes such as BAX or down-regulating transcription of survival genes such as BCL-2 ${ }^{[29]}$.

In the present study, cryptolepine caused a G1 arrest in HepG 2 and MCL-5 cells. Accompanying the G1 arrest was a massive up-regulation of p53 in both cell lines indicating that CLP-induced G1 arrest in these cell lines is p53-dependent. Furthermore, MDM2 levels increased in a similar pattern to the p53 accumulation, consistent with the notion that the
MDM2 gene is a direct target for positive transcriptional activation by $\mathrm{p} 53^{[16,30]}$.

In our experiments, p53 up-regulation was associated with increased expression of its target cdk inhibitor, p21, but a hypo-diploid peak (apoptotic cells) was also observed in the cell cycle studies. The ability of p53 to effect a G1 arrest, as observed in the current studies using HepG2 and MCL-5 cells, depends on the transcriptional regulation of its target genes particularly $\mathrm{p} 21^{\text {Waf1/Cip1 }}$, a cdk inhibitor capable of silencing the cdks that are essential for $S$ phase entry ${ }^{[31]}$. p21 levels were elevated by cryptolepine treatment in HepG2 and MCL-5 cells. The increase however lagged that of p53 indicating that as expected, the rise in p21 was dependent on p53. Together, these observations strongly suggest that the G1 arrest in these cell lines was p53- and p21-dependent.

The cyclins are key proteins that regulate the transition through the cell cycle ${ }^{[32]}$. Cyclin dependent kinases (cdks) are serine/threonine kinases that become activated when associated with the cyclins. Cell cycle progression is strictly controlled by cdk complexes consisting of catalytic subunits (cdks) and regulatory subunits (cyclins) ${ }^{[33]}$. For example, cyclin D increases in early to mid G1 phase and regulates Cdk4 and Cdk6. $\mathrm{pRB}$ is phosphorylated or dephosphorylated at different stages of the cell cycle ${ }^{[34]}$. Under normal conditions, $\mathrm{pRB}$ is maintained in an underphosphorylated active state through much of the G1 phase and becomes inactivated by further phosphorylation in the late G1 phase, releasing sequestered E2F family transcription regulators, which enable cells to progress to the $S$ phase $^{[35,36]}$. Cyclin D1/Cdk4 activity is required for this phosphorylation and without phosphorylation, $\mathrm{pRB}$ maintains it's binding to E2F and S phase progression is prevented, leading to G1 arrest. In addition, p53dependent induction of $\mathrm{p} 21$ leads to $\mathrm{pRB}$ dephosphorylation and consequent G1 arrest $^{[37]}$.

In the present study, CLP induced G1 arrest, upregulated p53 and p21 and promoted the dephosphorylation of hyperphosphorylated $\mathrm{pRB}$. These findings are consistent with evidence showing that $\mathrm{pRB}$ is an important requirement in G1 arrest induced by a variety of DNA damaging agents ${ }^{[38]}$. Cyclin D/Cdk4 facilitates the synthesis of cyclin $\mathrm{E}$ in late G1 phase, which in turn activates cdk2, cyclin A production and DNA synthesis. The decrease in the levels of cyclin $\mathrm{D}_{1}$ and A by cryptolepine in our experiments is therefore consistent with the decrease in hyperphosphorylated $\mathrm{pRB}$ and the observed G1 arrest. Like other DNA damaging agents, this study has shown that in p53 wildtype cells, CLP triggers a checkpoint action and delays cell cycle progression. The cryptolepine-induced cycle 
delay would presumably allow sufficient time for DNA repair to ensure fidelity before entry into mitosis or induce cell death in susceptible cells.

The ability of CLP to cause G2 arrest in SKOV3, a p53-null cell line and the induction of G1 arrest in a wild-type p53 cell line (HepG2) is intriguing but not surprising. The G2 arrest in SKOV3 is likely to be due to the topo II inhibitory action of the agents. In the HepG2 cells, the p53-mediated G1 arrest probably overrides any topo II inhibition since G1 arrest would precede mitosis where topo II function is required. Furthermore, p53 is known to mediate the transcriptional repression of topo $\mathrm{II}^{[39]}$. It is expected therefore that in wild-type p53 cell lines, p53-dependent G1 arrest would predominate over topo II mediated G2 arrest. Though it is not always possible to generalize or predict the effect of an agent on a particular cell line or groups of cell lines, this study shows that cryptolepineinduced cell cycle perturbation depends on the p53 status of the cell line. Irrespective of the p53 status, cryptolepine induces an increase in the sub-G1 population, indicative of cell death. However, in p53 wild-type cells (HepG2 and MCL-5), the accompanying cell death was lower than that reported for V79 cells (mutant p53) $^{[4]}$. Since p53 is mutated in most tumors ${ }^{[40]}$ it appears reasonable to suggest that cryptolepine may be selectively toxic to tumor cells. The advantage offered by such an anti-cancer agent is likely to be valuable. The potent cell-kill action of cryptolepine, its ability to suppress clonal expansion ${ }^{[4]}$ and induction of cell cycle arrest as demonstrated in the present study favor its anti-cancer potential.

\section{CONCLUSION}

Overall, the study shows that, though cryptolepine is cytotoxic irrespective of the p53 status of the cell line, its effect on the cell cycle appears to depend on the p53 status of the cell line. The potent cell-kill action of cryptolepine and its ability to evoke cell cycle arrest in susceptible cells favor its anticancer potential.

\section{AKNOWLEDGEMENT}

CA thanks the Commonwealth Scholarship Commission for a graduate scholarship.

\section{REFERENCES}

1. Dwuma-Badu, D., J.S.K. Ayim, N.I.Y. Fiagbe, J.E. Knapp, P.L. Schiff Jr. and D.J. Slatkin, 1978. Constituents of West African medicinal plants XX: Quindoline from Cryptolepis sanguinolenta. J. Pharm. Sci., 67: 433-434. DOI: 10.1002/JPS.2600670350
2. Tachie, A.N., M.H.M. Sharaf, P.L. Schiff, G.L. Boye, R.C. Crouch and G.E. Martin, 1991. Assignment of the proton and carbon NMR spectra of the indoloquinoline alkaloid cryptolepine. J. Heterocyclic Chem., 28: 1429-1435. DOI: 10.1002/jhet.5570280540

3. Bonjean, K., M.C. De Pauw-Gillet, M.P. Defresne, P. Colson, C. Houssier, L. Dassonneville and L. Angenot et al., 1998. The DNA intercalating alkaloid cryptolepine interferes with topoisomerase II and inhibits primarily DNA synthesis in B16 melanoma cells. Biochemistry, 37: 5136-5146. DOI: 10.1021/BI972927Q

4. Ansah, C. and N.J. Gooderham, 2002. The popular herbal antimalarial, extract of Cryptolepis sanguinolenta, is potently cytotoxic. Toxicol. Sci., 70: 245-251. DOI: $10.1093 / \mathrm{TOXSCI} / 70.2 .245$

5. Dassonneville, L., A. Lansiaux, A. Wattelet, N. Wattez, C. Mahieu and C. Bailly et al., 2000. Cytotoxicity and cell cycle effects of the plant alkaloids cryptolepine and neocryptolepine: relation to druginduced apoptosis. Eur. J. Pharmacol., 409: 9-18. DOI: 10.1016/S0014-2999(00)00805-0

6. Lisgarten, J.N., M. Coll, J. Portugal, C.W. Wright and J. Aymami, 2002. The antimalarial and cytotoxic drug cryptolepine intercalates into DNA at cytosine-cytosine sites. Nat. Struct. Biol., 9: 57-60. DOI: $10.1038 / \mathrm{NSB} 729$

7. Ansah, C. and N.J. Gooderham, 2005. Reactive oxygen species is associated with cryptolepine cytotoxicity. J. Sci. Technol., 25: 1-10 http://ajol.info/index.php/just/article/view/32926

8. Ansah, C., H. Zhu and N.J. Gooderham, 2008. The mechanism of cryptolepine-induced cell death. J. Pharmacol. Toxicol., 3: 291-301. DOI: 10.3923/JPT.2008.291.301

9. Livingstone, L.R., A. White, J. Sprouse, E. Livanos, T. Jacks and T.D. Tlsty, 1992. Altered cell cycle arrest and gene amplification potential accompany loss of wild-type p53. Cell, 70: 923-935. DOI: 10.1016/0092-8674(92)90243-6

10. Volgestein, B., D. Lane and A.J. Levine, 2000. Surfing the p53 network. Nature, 408: 307-310. DOI: $10.1038 / 35042675$

11. Chaung, W., L.J. Mi and R. Boorstein, 1997. The p53 status of Chinese hamster V79 cells frequently used for studies on DNA damage and DNA repair. Nucleic Acid Res., 25: 992-994. DOI: 10.1093/NAR/25.5.992

12. Morris, S.M., M.G. Manjanatha, S.D. Shelton, O.E. Domon, L.J. McGarrity and D.A. Casciano, 1996. A mutation in the p53 tumor suppressor gene of AHH-1 tk+/- human lymphoblastoid cells. Mutat. Res., 356: 129-134. DOI: 10.1016/00275107(96)00133-9 
13. Kim, J.M., Y.D. Yoon and B.K. Tsang, 1999. Involvement of the Fas ligand in p53-mediated granulosa cell apoptosis during follicular development and atresia. Endocrinology, 140: 2307-2317. DOI: 10.1210/EN.140.5.2307

14. Crespi, C.L., F.J. Gonzalez, D.T. Steimel, T.R. Turner, H.V. Gelboin, B.W. Penman and R.A. Langenbach, 1991. Metabolically competent human cell line expressing five cDNAs encoding procarcinogenactivating enzymes: Application to mutagenicity testing. Chem. Res. Toxicol., 4: 566-72. DOI: 10.1021/TX00023A013

15. El-Deiry, W.S., T. Tokino, V.E. Velculescu, D.B. Levy, R. Parsons and B. Vogelstein et al., 1993. WAF1, a potential mediator of p53 tumor suppression. Cell, 75: 817-25. DOI: 10.1016/00928674(93)90500-P

16. Barak, Y., T. Juven, R. Haffner and M. Oren, 1993. $\mathrm{Mdm} 2$ expression is induced by wild-type p53 activity. EMBO. J., 12: 461-468. http://www.ncbi.nlm.nih.gov/pubmed/8440237

17. Noamesi, B.K., A. Paine, G.C. Kirby, D.C. Warhurst and G.D. Philipson, 1991. In vitro anti-malarial action of cryptolepine, an indoquinoline. Trans. R. Soc. Trop. Med. Hyg., 85: 315.

18. Kirby, G.C., A. Paine, D.C. Warhurst, B.K. Noamesi and. J.D. Philipson, 1995. In vitro and in vivo antimalarial activity of cryptolepine, a plant derived indoquinoline. Phytother. Res., 9: 359-363. DOI: 10.1002/PTR.2650090510

19. Wright, C.W., J.D. Philipson, S.O. Awe, G.C. Kirby, D.C. Warhurst et al., 1996. Antimalarial action of cryptolepine and some other anhydronium bases. Phytother. Res., 10: 361-363. DOI: 10.1002/(SICI)10991573(199606)10:4<361::AIDPTR845>3.0.CO;2-N

20. Dassonneville, L., K. Bonjean, M.C. De Pauw-Gillet, P. Colson, C. Houssier and C. Bailly et al., 1999. Stimulation of topoisomerase II-mediated DNA cleavage by three DNA-intercalating plant alkaloids: Cryptolepine, matadine and serpentine. Biochemistry, 38: 7719-26. $\quad$ DOI: 10.1021/BI990094T

21. Clifford, B., M. Beljin, G.R. Stark and W.R. Taylor, 2003. G2 arrest in response to topoisomerase II inhibitors: The role of p53. Cancer Res., 63: 4074-81. http://www.ncbi.nlm.nih.gov/pubmed/12874009

22. Chow, K.C. and W.E. Ross, 1987. Topoisomerasespecific drug sensitivity in relation to cell cycle progression. Mol. Cell Biol., 7: 3119-3123. http://www.ncbi.nlm.nih.gov/pubmed/2823120
23. Ross, D., W. Thomas and C. Holm, 1990. Degradation of recombined chromosomes in meiosis I requires topoisomerase II. Cell, 60: 1009-1017. DOI: 10.1016/0092-8674(90)90349-J

24. Lane, D.P., 1992. p53: guardian of genome. Nature, 358: 15-16. DOI: 10.1038/358015a0

25. Hartwell, L.H. and T.A. Weinert, 1989. Checkpoints: Controls that ensure the order of cell cycle events. Science, 246: 629-34. DOI: 10.1126/SCIENCE.2683079

26. Gottlieb, T.M. and M. Oren, 1996. p53 in growth control and neoplasia. Biochim. Biophys. Acta, 1287: 77-102. DOI: 10.1016/0304-419x(95)00019-C

27. Ko, L.J. and C. Prives, 1996. p53: Puzzle and paradigm. Genes Dev., 10: 1054-72. DOI: 10.1101/GAD.10.9.1054

28. Levine, A.J., 1997. p53, the cellular gatekeeper for growth and division. Cell, 88: 323-31. DOI: 10.1016/S0092-8674(00)81871-1

29. Miyashita, T., S. Krajewski, M. Krajewska, H.G. Wang and H.K. Lin et al., 1994. Tumor suppressor p53 is a regulator of bcl-2 and bax gene expression in vitro and in vivo. Oncogene, 9: 1799-805. http://www.ncbi.nlm.nih.gov/pubmed/8183579

30. Juven, T., Y. Barak, A. Zauberman, D.L. George and M. Oren, 1993. Wild-type p53 can mediate sequence specific transactivation of an internal promoter within the MDM2 gene. Oncogene, 8: 3411-3416. http://www.ncbi.nlm.nih.gov/pubmed/8247544

31. Sherr, C. and J.M. Roberts, 1999. CDK inhibitors: positive and negative regulators of G1 phase progression. Genes Dev., 13: 1501-1512. DOI: 10.1101/GAD.13.12.1501

32. Roberts, J.M., 1999. Evolving ideas about cyclins. Cell, 98: 129-132. http://www.cell.com/biophysj/abstract/S09628924(97)01114-8

33. Sandal, T., 2002. Molecular aspects of the mammalian cell cycle and cancer. Oncologists, 7: 73-81.

http://theoncologist.alphamedpress.org/cgi/content/ abstract/7/1/73

34. Chen, P.L., P. Scully, J.Y. Shew, J.Y. Wang and W.H. Lee, 1989. Phosphorylation of the RB gene product is modulated during the cell cycle and cellular differentiation. Cell, 58: 1193-1198. http://www.cell.com/comments/0092-8674(89)90517-5

35. Riley, D.L., E.Y. Lee and W.H. Lee, 1994. The pRB: More than a tumor suppressor. Ann. Rev. Cell Biol., 10: 1-29. DOI: 10.1146/ANNUREV.CB.10.110194.000245 
36. Weinberg, R.A., 1995. The molecular basis of oncogenes and tumor suppressor genes. Ann. N. Y. Acad. Sci., 758: 331-338. DOI: 10.1111/j.17496632.1995.tb24838.x

37. Hartwell, L.H. and M.B. Kastan, 1994. Cell cycle control and cancer. Science, 266: 1821-1828. DOI: 10.1126/SCIENCE.7997877

38. Harrington, E.A., J.L. Bruce, E. Harlow and N. Dyson, 1998. pRB plays an essential role in cell cycle arrest induced by DNA damage. Proc. Natl. Acad. Sci. USA., 95: 11945-50. http://ukpmc.ac.uk/articlerender.cgi?artid=270037
39. Wang, Q., G. P. Zambetti and D.P. Suttle, 1997. Inhibition of DNA Topoisomerase II $\alpha$ gene expression by the p53 tumor suppressor. Mol. Cell Biol., $\quad$ 17: 389-397. http://www.pubmedcentral.nih.gov/picrender.fcgi? artid $=231763 \&$ blobtype $=$ pdf

40. Soussi, T., 2000. The p53 tumor suppressor gene: From molecular biology to clinical investigation. Ann. N. Y. Acad. Sci., 910: 121-139. http://www.ncbi.nlm.nih.gov/pubmed/10911910 